\title{
Gender Bias and the Journal of Roman Studies
}

\author{
$J R S$ EDITORIA L B O A R
}

\section{INTRODUCTION}

Reflecting on present unease about structural biases in the discipline, and aiming to offer a data-rich response to some recent criticisms of this Journal, the Editorial Board has undertaken a study of the representation of female scholars in the Journal of Roman Studies. To that end, we have gathered data on publications, submissions and JRS Editorial Board membership for the past fifteen years, from Volume 95 (2005) through to the present volume, Volume Io9 (2019). The data are set out in the final section (VII), following a brief review of the main results. Our goal here is neither to present a definitive analysis, nor to offer a commentary on the underlying causes of the patterns revealed (on which we expect much fruitful discussion elsewhere). Rather, the JRS Editorial Board aims to make key data available both to inform a much wider debate within the profession as a whole and, importantly, to inform this Journal's policies, procedures and active outreach. The Board is also acutely aware that any analysis of gender bias needs to be framed carefully - both by an awareness that there are other under-represented groups in the discipline (on which our data in their current form would regrettably only offer a most imperfect picture), and by a sensitivity to the limitations of a conception of gender as a simple binary.

The interpretation of the data requires some initial sense of the overall representation of female scholars in the profession. In the case of an international journal such as the Journal of Roman Studies, which regularly publishes work by scholars from across Europe and North America, this is complicated by significant differences between countries. Nor can the overall gender breakdown of active researchers in Classical Studies be established with any real precision: in addition to postholders in universities and colleges, the category (ideally) ought to embrace retired academics, independent scholars, postgraduate students and individuals employed in museums and national archaeological services. Add to which significant differences in the nature of the post held: permanent, adjunct, fixed-term, part-time. It is important to emphasise right at the outset that any statistics on the gender make-up of the 'profession as a whole' are therefore bound to be somewhat impressionistic.

Currently available data (to be taken with the reservations and limitations outlined above) suggest that the situations in Classics in North America and the UK are broadly similar. In the UK, women made up 47 per cent of postholders (both fixed-term and permanent) and 34 per cent of professors in 20I7-20I8 (CUCD). Up-to-date data for Classics in North America are harder to find. In 2012, women were 40 per cent of postholders (tenured and untenured, full-time and part-time) in US institutions (American Academy of Arts and Sciences); in 2006-2007 they were 37 per cent of postholders (all ranks) and 28 per cent of full professors in the USA and Canada combined. We have not seen comparable data for other European countries, nor from other parts of the world from which $J R S$ regularly receives submissions and commissions reviews.

JRS I09 (20I9), pp. 44I-448. (C) The Author(s) 20I9. The Society for the Promotion of Roman Studies. This is an Open Access article, distributed under the terms of the Creative Commons Attribution licence (bttp://creativecommons.org/ licenses/by/4.o/), which permits unrestricted re-use, distribution, and reproduction in any medium, provided the original work is properly cited. 


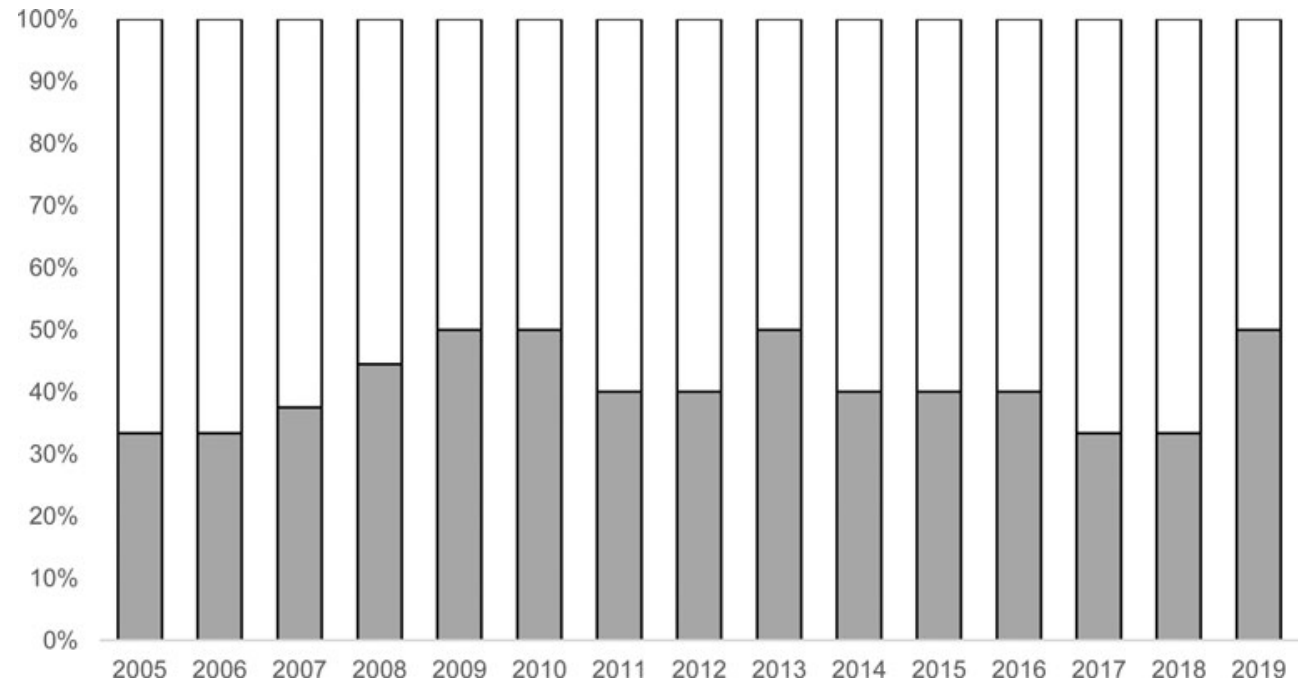

FIG. I. Representation of women on the Editorial Board.

II EDITOR AND EDITORIAL BOARD

Since 2005, the post of Editor has been held by Alison Sharrock (2005-2007), Greg Woolf (2008-20I3), Catherine Steel (2014-2017) and Christopher Kelly (2018-20I9). The Journal has had a female editor for seven of the fifteen years covered by this review.

The Editor is assisted by an Editorial Board which conducts the bulk of peer review of submissions. The size of the Board has gradually increased from eight/nine in 2005-2009 to ten in 20IO-20I7 and twelve in 20I8-20I9. The average representation of women on the Board (including the Editor) was 4I per cent over the whole period. There is some natural fluctuation from year to year as the Board renews itself and tries to maintain a balance of expertise (as well as seniority and geographical distribution), with the annual figure for the representation of women ranging between 33 per cent (in 2005-20I6 and again in 20I7-20I8) and 50 per cent (in 2009-20IO, 20I3 and again in 20I9) (Fig. I). Overall, the proportion does not seem out of line with the representation of women among mid-career/professorial scholars at UK departments (from which the Board is normally recruited).

\section{ARTICLES}

In recent years (2005-20I9), the Journal has published an average of nine articles per year. Each article is reviewed by two to three members of the Editorial Board (those accepted and published often by five). Highly specialist pieces are occasionally referred to an external reviewer for an additional opinion, as are all submissions from members of the Editorial Board itself. All reviewing is strictly double-blind: the identity of the author is known to the Editor, but not to any of the members of the Editorial Board reading it (save for a very small number of cases where anonymisation is impossible).

Over the fifteen volumes from 2005 to 2019 inclusive, the Journal has published I 29 articles, excluding commissioned surveys and reviews, which are discussed separately below. 22 per cent were written by women. For the purpose of this calculation, joint authors are each counted as an appropriate fraction. For example, Lisa Eberle and Enora Le Quéré, joint authors of an article in JRS 2017, each count as 0.5 for the tally. 


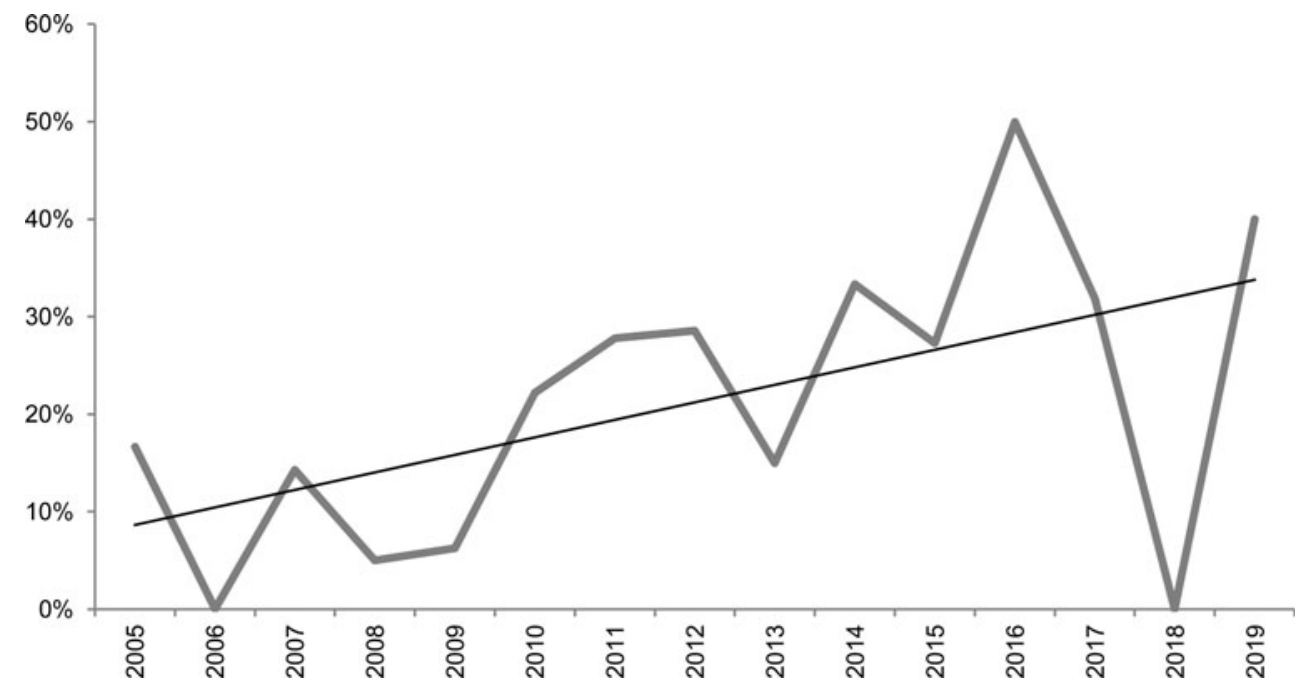

FIG. 2. Representation of female authors by volume.

There has been a gradual increase in the representation of female authors over the period. Given the small number of articles published each year, the annual figure is highly volatile: 2018 was anomalously low with $\circ$ per cent, but 2019 jumped back above trend with 40 per cent (Fig. 2). Nevertheless, a gradual upwards trend is clear (see the trendline in Fig. 2). Aggregating the data to smooth out fluctuations, the proportion of contributions by female authors has increased from 8 per cent in 20052009 to 25 per cent in 20IO-20I4 and 30 per cent in 20I5-20I9. Nevertheless, the representation of women amongst $J R S$ authors remains lower than their overall representation in the profession, at least in the UK and North America.

\section{COMMISSIONED SURVEY AND REVIEW ARTICLES}

The Journal publishes one or two substantial 'review articles' each year, covering particularly important new books or larger clusters of volumes. These 'review articles' are typically $5,000-8,000$ words in length, and are directly commissioned by the Reviews Editor in consultation with the rest of the Editorial Board.

Since 2005 , the Journal has published a total of nineteen 'review articles'. Fourteen of these 'review articles' were authored by male scholars (in one instance by a pair of male scholars); two were authored by a male-female pair; and three were authored by female scholars. Over the entire period, 2I per cent of 'review articles' have been female-authored (counting each member of a reviewing pair as 0.5 of the review's author). This is approximately equal to the proportion of articles ( 22 per cent), but significantly below that for reviews (40 per cent).

A similar imbalance is observable in the substantial 'survey articles' that have in the past occasionally been commissioned to provide a survey of recent scholarship on a particular topic (the most familiar being the series on 'Roman Inscriptions', the last and final of which appeared in 20I2). 'Survey articles' have historically been commissioned by the Editor in consultation with the rest of the Editorial Board. The Journal published five 'survey articles' in the period 2005-2019, three with a sole male author and two with a mixed team. The overall rate of female authorship was 17 per cent. When compared to the 
rates for reviews and articles, it does appear that the Journal's Editorial Board has historically been considerably less willing to commission substantial review articles and survey articles from female scholars.

\section{REVIEWS}

The Journal of Roman Studies has a single Reviews Editor responsible for commissioning book-reviews. Since 2004, the post of Reviews Editor has been held by Christopher Smith (2004-2006), Greg Woolf (2007-2008), Catherine Steel (2009-2013), Christopher Kelly (20I4-20I7) and Peter Thonemann (20I8-20I9). The Journal has had a female reviews editor for five of the fifteen years covered by this review.

The Journal typically publishes between seventy and a hundred reviews each year. Reviews of single volumes are normally 900-1,200 words long. Each year the Journal publishes a handful of reviews covering multiple volumes on a single theme, which can be up to 2,400 words in length. The more substantial 'review articles' are discussed separately above. At present the Journal typically carries only a single review from each reviewer per issue, but in the past it was more frequent for individual reviewers to publish several discrete reviews in a single issue; for example, $J R S$ IO3 (2013) includes four reviews by Michael Crawford (covering a total of thirteen volumes).

A handful of reviews were co-authored by two individuals. For the purpose of analysis, each of the reviewing pair is counted as 0.5 of the review's author, as for articles and submissions. (In 20I 8, for example, the number 'seventy-eight' in fact represents eighty discrete reviewers, since one review was co-authored by Valentina Grasso and Garth Fowden, another by Martin Dinter and Astrid Khoo.) Where a single reviewer produced several separate reviews in a single issue, these are counted separately (so Michael Crawford is in fact four of the forty-nine male reviewers in 2013).

Over the entire period 2005-2019, the Journal has published I,255 reviews (excluding review articles), of which 754.5 (60 per cent) were male-authored and 500.5 (40 per cent) female-authored. Fig. 3 tracks the gender breakdown of authors of reviews between 2005 and 20I9. It is noteworthy that the shift from a male to a female Reviews Editor in 2008 coincided with a significant increase in the proportion of female-authored reviews from 2009 onwards (the time-lag between commissioning and publication is typically between one and two years).

The overall trend is towards a gradual increase in the proportion of female-authored reviews (see trendline in Fig. 3) that appears broadly in line with the proportion of female postholders in Classical Studies in US and UK universities.

\section{SUBMISSIONS}

Any potential bias in the editorial process can only be identified by comparing published articles to submitted manuscripts (while noting that the balance of submissions may itself be affected by other factors, including the image and reputation of the Journal). We have collated editorial data for submissions for the period June 2009 to May 20 I9. (The greater difficulty involved in recovering historic editorial data has prevented us from pursuing this further back to 2005.) The data have been corrected for resubmissions, to ensure that each published article only counts as a single submission. Joint-authored submissions are counted in the same way as joint-authored articles. We assume that articles published in, for example, November 2019 (that is in the annual print version of the Journal) were submitted during the period June 20 I 8 to May 20 I9. There are inevitably some exceptions, but they should not affect the analysis. The 


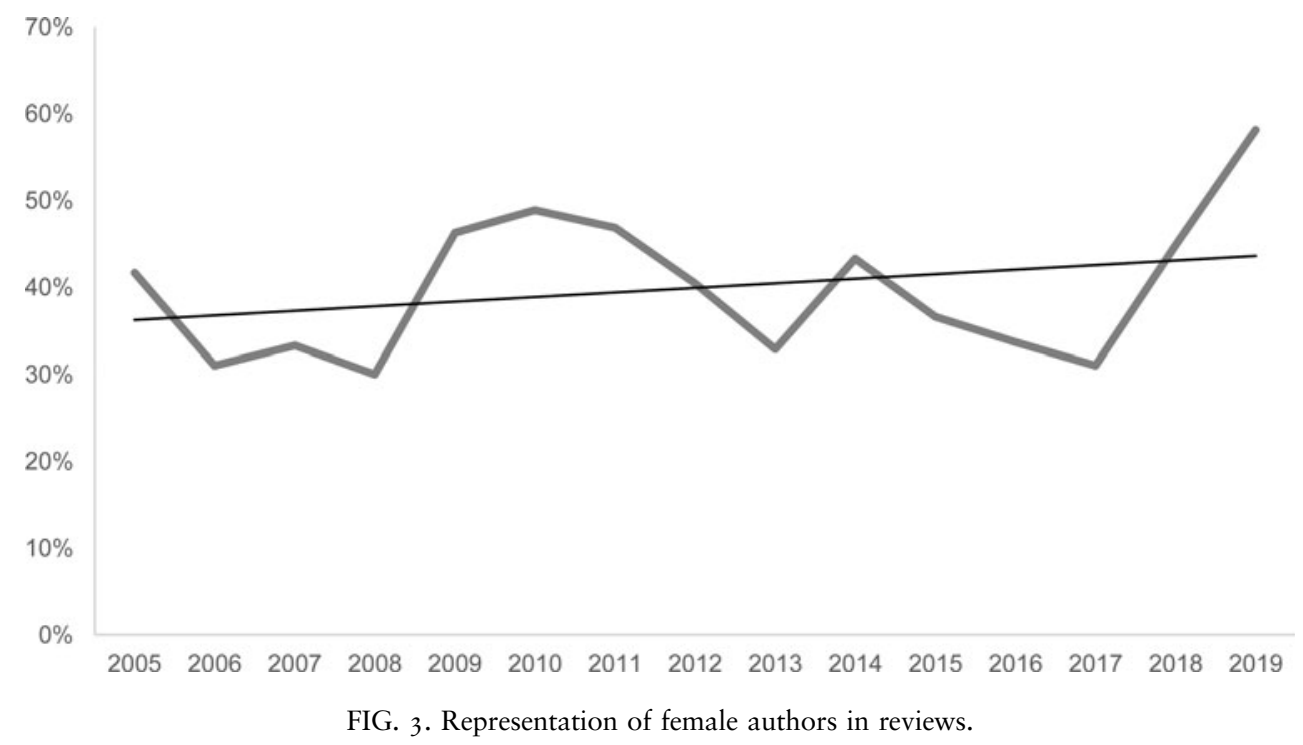

Journal received 642 submissions during the ten-year period June 2009 to May 20I9. Set against the ninety-two articles published in the corresponding volumes (2010-2019), this implies an average acceptance rate of I 4.3 per cent.

The rate of female authorship in the 642 submissions was 30 per cent, almost identical to that of 28 per cent in the ninety-two articles published in volumes 2010-2019 (and somewhat higher than the 22 per cent in 2005-2019). This indicates that the imbalance in published articles is almost entirely due to a similar imbalance in submissions. There is a small discrepancy in success rates: whereas the overall average acceptance rate was I 4.3 per cent, the rate for female authors was I 3.0 per cent and that for male authors I 4.6 per cent. This discrepancy is not, however, significantly significant (the hypothesis of a gender bias is rejected with a chi-squared test at the 0.05 level of significance). In other words: in a sample of this size, the slight imbalance could easily have arisen by chance, even if male and female authors had equal chance of having their submissions accepted.

The overall figure may nevertheless obscure some chronological developments. As with publications, the annual acceptance rates are highly volatile (Fig. 4). Fig. 5 presents the three-year rolling average success rates to smooth out the fluctuation. It can be observed that the rates for men and women are broadly similar and that the rate for women is more volatile year-to-year (as expected, given the small sample size). But there was a period 20I4-20I7 in which relative success rates were inverted (with 17 per cent for women vs I 3 per cent for men, compared to Io per cent for women and I7 per cent for men in 20IO-20I3). It may be significant that this largely coincides with the time in which the Editorship was held by a woman (Catherine Steel in 20I3-20I6). But any causal effect must have been complex given the double-blind reviewing system. The pattern may also have arisen by chance. The high volatility in 2018-20I9 makes more recent trends hard to discern.

Overall, female authors do appear to have been significantly under-represented in JRS articles over the past fifteen years (compared to their representation among postholders), but the imbalance seems to be almost entirely attributable to a comparable imbalance in submissions to the Journal. If there has been any gender bias, it appears to have been relatively small and transient. The Editorial Board sees no need to change its current practice for reviewing submissions and certainly no grounds for departing from the 


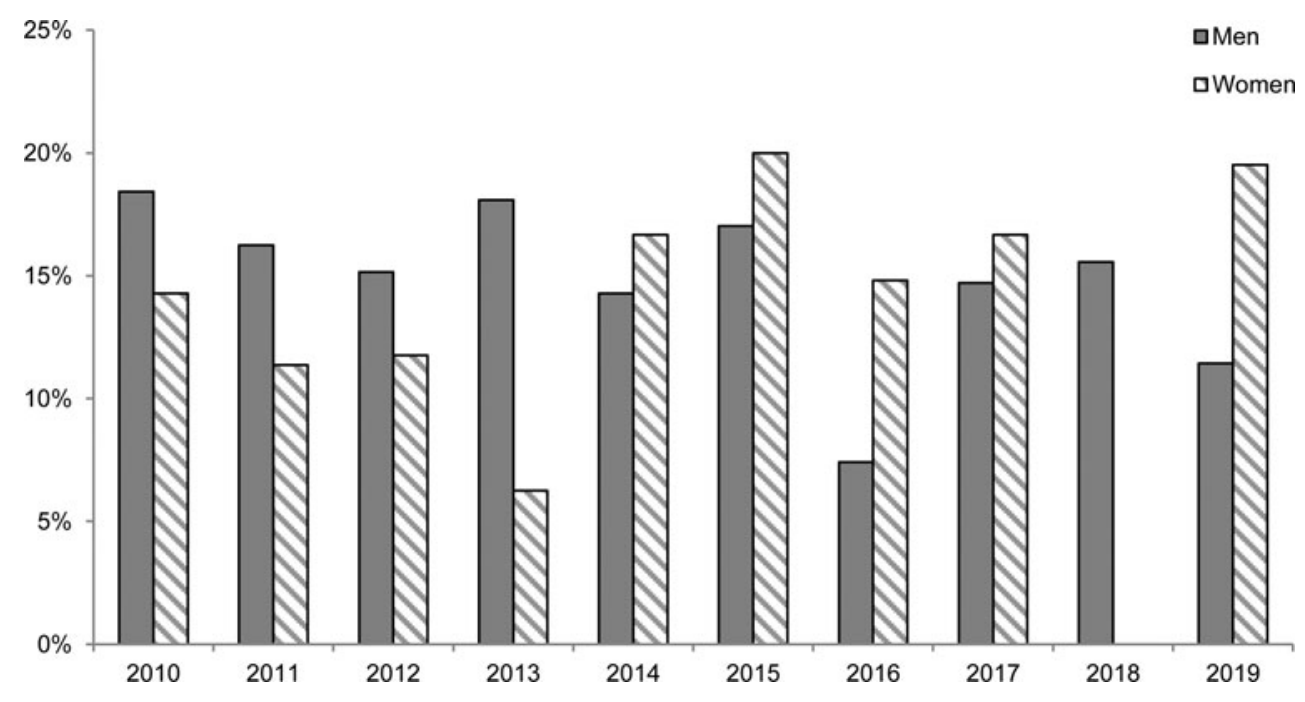

FIG. 4. Acceptance rate by gender and volume.

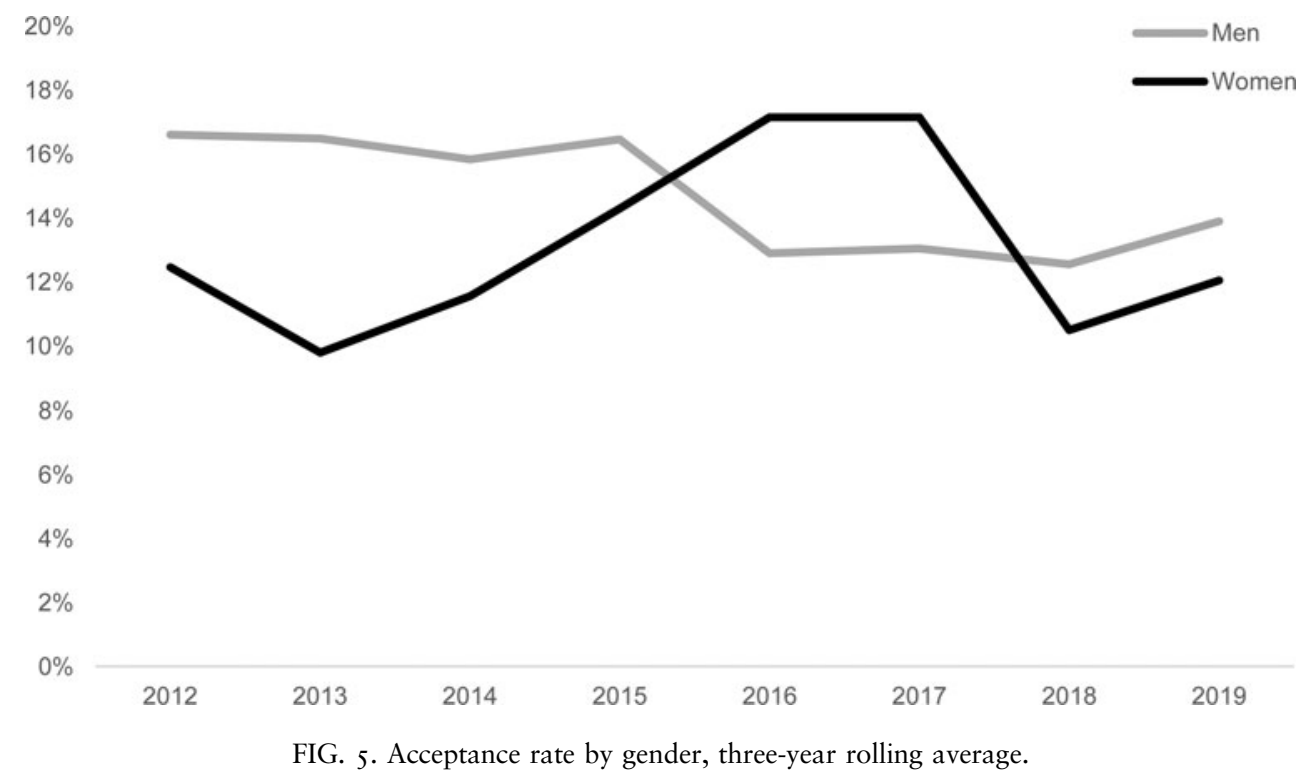

principle of double-blind reviewing. Indeed, the results appear to confirm the merits of the double-blind principle in reducing gender bias in reviewing. We are, however, actively reviewing our current policies and procedures as part of a firm and on-going commitment to address - insofar as we are able - the imbalance in submissions to the Journal, while recognising that progress also depends on wider discussion and reform in the profession as a whole. 


\begin{tabular}{|c|c|c|c|c|c|c|c|c|c|c|c|c|c|c|}
\hline \multirow[b]{2}{*}{ VOL. } & \multirow[b]{2}{*}{ YEAR } & \multirow[b]{2}{*}{ EDITOR } & \multicolumn{2}{|c|}{$\begin{array}{l}\text { EDITORIAL } \\
\text { BOARD }\end{array}$} & \multicolumn{2}{|c|}{ ARTICles } & \multicolumn{2}{|c|}{$\begin{array}{l}\text { SubMISSIONS } \\
\text { PREVIOUS } \\
\text { JUNE-MAY }\end{array}$} & \multicolumn{2}{|c|}{ Reviews } & \multicolumn{2}{|c|}{$\begin{array}{c}\text { REVIEW } \\
\text { ARTICLES }\end{array}$} & \multicolumn{2}{|c|}{$\begin{array}{c}\text { SURVEY } \\
\text { ARTICLES }\end{array}$} \\
\hline & & & $\mathrm{M}$ & $\mathrm{F}$ & $\mathrm{M}$ & $\mathrm{F}$ & $\mathrm{M}$ & $\mathrm{F}$ & $\mathrm{M}$ & $\mathrm{F}$ & $\mathrm{M}$ & $\mathrm{F}$ & $\mathrm{M}$ & $\mathrm{F}$ \\
\hline 95 & 2005 & $\mathrm{~F}$ & 6 & 3 & 5 & $\bar{I}$ & na & na & 42 & 30 & I.O & & I.O & 0.0 \\
\hline 96 & 2006 & $\mathrm{~F}$ & 6 & 3 & 7 & o & na & na & 49 & 22 & I.O & & & \\
\hline 97 & 2007 & $\mathrm{~F}$ & 5 & 3 & 6 & I & na & na & 54 & 27 & & & 0.7 & 0.3 \\
\hline 98 & 2008 & $\mathrm{M}$ & 5 & 4 & 9.5 & 0.5 & na & na & 49 & $2 I$ & & & & \\
\hline 99 & 2009 & $\mathrm{M}$ & 4 & 4 & $7 \cdot 5$ & 0.5 & na & na & 36 & $3 \mathrm{I}$ & $3 \cdot 5$ & 0.5 & & \\
\hline IOO & 2010 & $\mathrm{M}$ & 5 & 5 & 7 & 2 & 38 & I4 & 46 & 44 & 0.5 & 0.5 & I.O & 0.0 \\
\hline IOI & $20 I I$ & $\mathrm{M}$ & 6 & 4 & 6.5 & 2.5 & 40 & 22 & 42 & 37 & 2.0 & & & \\
\hline IO2 & 2012 & $\mathrm{M}$ & 6 & 4 & 5 & 2 & 33 & I7 & 53 & 36 & I.O & & 0.5 & 0.5 \\
\hline IO3 & 2013 & $\mathrm{M}$ & 5 & 5 & 8.5 & I. 5 & 47 & 24 & 49 & 24 & I.O & & & \\
\hline IO4 & 2014 & $\mathrm{~F}$ & 6 & 4 & 6 & 3 & 42 & I 8 & 59 & 45 & & I.O & & \\
\hline 105 & 2015 & $\mathrm{~F}$ & 6 & 4 & 8 & 3 & 47 & I 5 & $7 \mathrm{I}$ & $4 \mathrm{I}$ & I.O & & & \\
\hline 106 & 2016 & $\mathrm{~F}$ & 6 & 4 & 4 & 4 & 54 & 27 & 59 & 30 & 2.0 & & I.O & 0.0 \\
\hline 107 & 2017 & $\mathrm{~F}$ & 6 & 3 & $7 \cdot 5$ & $3 \cdot 5$ & $5 \mathrm{I}$ & $2 I$ & 69 & $3 \mathrm{I}$ & & & & \\
\hline IO8 & 20 I 8 & $\mathrm{M}$ & 8 & 4 & 7 & 0 & 45 & I7 & 43 & 35 & I.O & I.O & & \\
\hline 109 & 2019 & $\mathrm{M}$ & 6 & 6 & 6 & 4 & 52.5 & 20.5 & $33 \cdot 5$ & 46.5 & I.O & I.O & & \\
\hline
\end{tabular}


Christopher Kelly (Cambridge) (Editor)

cmkı I@cam.ac.uk

Peter Thonemann (Oxford) (Reviews Editor)

peter.thonemann@wadham.ox.ac.uk

Barbara Borg (Exeter)

b.e.borg@exeter.ac.uk

Julia Hillner (Sheffield)

j.hillner@sheffield.ac.uk

Myles Lavan (St Andrew's)

mpl2@st-andrews.ac.uk

Neville Morley (Exeter)

N.D.G.Morley@exeter.ac.uk

Alex Mullen (Nottingham)

alex.mullen@nottingham.ac.uk

Silvia Orlandi (Rome)

silvia.orlandi@uniromar.it

Emily Pillinger (London)

emily.pillinger@kcl.ac.uk

Jonathan Prag (Oxford)

jonathan.prag@merton.ox.ac.uk

Henriette van der Blom (Birmingham)

h.vanderblom@bham.ac.uk

Christopher Whitton (Cambridge)

clw36@cam.ac.uk 